\title{
INVESTIGATION OF NEUTRAL AXIS SHIFTING AND WALL THICKNESS DISTRIBUTION OF BENT TUBES PRODUCED BY ROTARY DRAW BENDING
}

\author{
Univ.-Prof. Dr.-Ing. B. Engel, M.Sc. H. Hassan
}

\begin{abstract}
Rotary draw bending is a method used for tube forming. During the tube bending process, the neutral axis moves towards the inner arc and the wall thickness changes in the cross section of the tube. Wall thinning of the tube takes place at the extrados, whereas wall thickening of the tube occurs at the intrados. This paper investigates the tube bending with rotary draw bending process using thick-walled tubes and different material properties (16Mo3 and 10CrMo9-10). The experimental tests and finite element simulations are used to calculate the variable characteristics (wall thickness distribution, neutral axis shifting and longitudinal strain distribution). These results are compared with results of a plasto-mechanical model. Moreover, the cross section distortion is investigated in this study. This study helped to get bends with smaller wall factor for different material properties.
\end{abstract}

Keywords - Rotary draw bending, thick-welled tube, material properties, material influence.

\section{INTRODUCTION}

$\mathrm{T}$ he NC bending process of thin-walled tubes have been attracting more and more applications in automobile, aviation, aerospace and various other high technology industries as well as it has also been satisfying the increasing needs for high strength / weight ratio products. The technology has become one of the main fields in the research and development of advanced plastic forming technology [1]. "The tube is inserted into the bending machine and clamped between the inner and the outer clamp die. By the rotation of both (inner clamp die and outer clamp die) around the bending axis, the tube is formed according to the radius of the bending die. The pressure die (slide piece) serves the purpose of taking up the radial stress, which is generated during the forming process and supports the straight tube end from the outside. If a mandrel and a wiper die are applied additionally (mandrel bending), high work piece quality can be achieved even with thin-walled tubes and small bending radii" [2]. Fig. 1 shows a sketch of the rotary draw bending process.

Prof. Dr.-Ing. Bernd Engel is the head the Chair of Forming Technology, Department of Mechanical Engineering, University of Siegen, 57076 Siegen, Germany.

M. Sc. Hassan Raheem Hassan is PhD student at the Chair of Forming Technology, Department of Mechanical Engineering, University of Siegen, 57076 Siegen, Germany. Master degree in University of Baghdad, Baghdad, Iraq

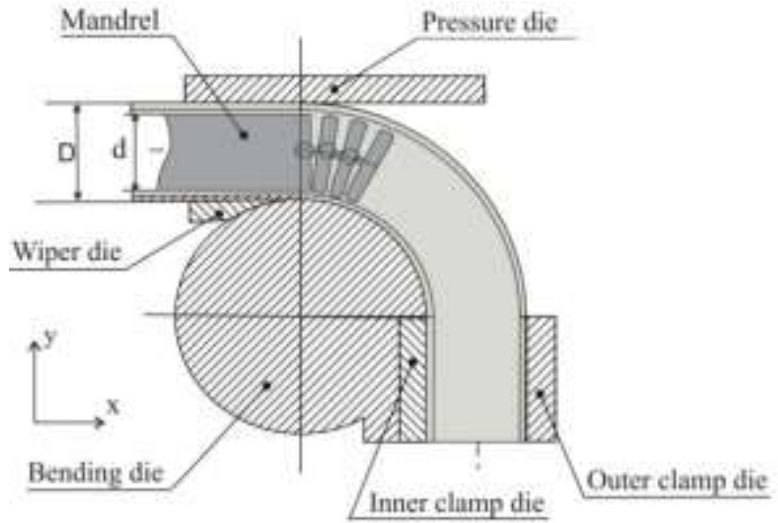

Figure 1: shows a sketch and tools of the rotary draw bending process.

In this study, the experimental tests show the variable characteristics (wall thickness distribution, neutral axis shifting and longitudinal strain distribution) in rotary draw bending using thick-walled tube with different material properties. In addition, an FE simulation of the rotary draw bending has been developed and compared with the results obtained from the experimental tests as well as the theoretical calculations. Theoretical calculations in tube bending based on a plasto-mechanical model that was presented by [3]

\section{A PLASTO-MECHANICAL MODEL}

A plasto mechanical model (Model II) has been developed to calculate the neutral axis shifting as well as a wall thickness distribution with different bending angles [3]. The maximum amount of the neutral axis shifting is determined according to equation derived from the theory plastic bending [4].

$$
\begin{aligned}
& \mathrm{R}^{\prime}=\sqrt{\left(\mathrm{R}_{\mathrm{b}}+\mathrm{r}\right) \cdot\left(\mathrm{R}_{\mathrm{b}}-\mathrm{r}\right)} \\
& \mathrm{e}_{\mathrm{i}}=\mathrm{R}_{\mathrm{b}}-\mathrm{R}^{\prime}
\end{aligned}
$$

Where $R_{b}$ is the bending radius (the distance from the center of the tube to the center of the bending die), $\mathrm{R}^{\prime}$ is the distance from the center of the bending die to the neutral axis after 
Proc. of the Third Intl. Conf. on Advances in Mechanical and Automation Engineering - MAE 2015.

Copyright (C) Institute of Research Engineers and Doctors, USA .All rights reserved.

ISBN: 978-1-63248-080-4 doi: 10.15224/ 978-1-63248-080-4-28

shifting and $e_{i}$ is the maximum amount of the neutral axis shifting using basic model. According to [5], the neutral axis shifting with different bending angle expresses as following:

$$
\mathrm{e}_{\alpha}=\frac{\mathrm{e}_{\mathrm{i}}}{\sin 45} \cdot \sin \left(\frac{\alpha}{2}\right)
$$

The model II is modified with material properties using the correction factor. The correction factor is a purely empirically determined. The correction factor is shown by the following equation:

$$
\mathrm{C}_{\mathrm{T}}=\ln \left|\mathrm{n} . \mathrm{B} \cdot \mathrm{W} \cdot \frac{1}{100}\right|
$$

Where $\mathrm{C}_{\mathrm{T}}$ is the correction factor, $\mathrm{n}$ is the strain hardening exponent, $\mathrm{B}$ is the bending factor and $\mathrm{W}$ is the wall factor. The following equations express a new neutral axis shifting in the tube and a new bending radius.

$$
\begin{aligned}
& \mathrm{e}_{\mathrm{A}}=\mathrm{e}_{\alpha} \mathrm{C}_{\mathrm{T}} \\
& \mathrm{R}_{\mathrm{A}}=\mathrm{R}_{\mathrm{b}}-\mathrm{e}_{\mathrm{A}}
\end{aligned}
$$

Where $e_{\alpha}$ is the distance of the neutral axis shifting and $R_{\alpha}$ is the bending radius according to [4]. $\mathrm{e}_{\mathrm{A}}$ is the distance of the neutral axis shifting and $\mathrm{R}_{\mathrm{A}}$ is the new bending radius after neutral axis shifted using the model II according to [3].

\section{EXPERIMENTAL TEST}

\section{A. Rotary draw bending}

The bending tests are carried out using a CNC bending machine that was produced by the Tracto-Technik GmbH \& CO.KG Company. This machine has been specially designed to be used in rotary draw bending and also for free-form bending, see Fig. 2.

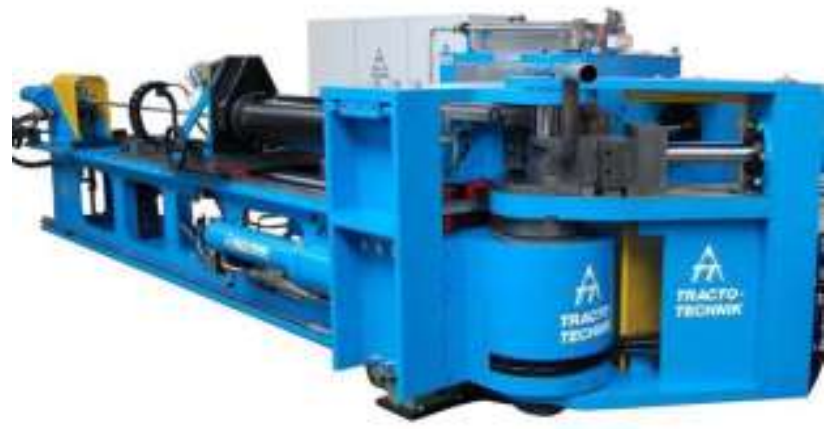

Figure 2: Rotary draw bending machine TT120UTS

\section{B. Measurement methods}

Wall thickness measurement devise

The wall thickness measuring device is used to measure the wall thickness distribution on the cross section of the tube. It consists of a calliper with an inductive sensor. The sensor signal is measured and converted by a computer-integrated A/D converter card with a 16 bit resolution. The high- resolution A / D converter provides a resolution of the electric field in the wall thickness of $0.6 \mu \mathrm{m}$. With careful calibration, an absolute accuracy can be achieved up to a value of about \pm $5 \mu \mathrm{m}$ or more, see Fig. 3.

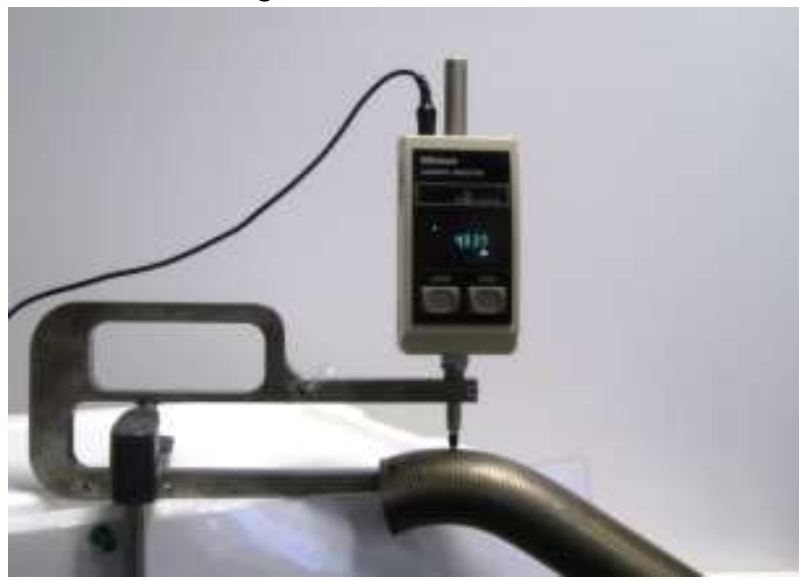

Figure 3: The wall thickness measuring device

Strain Measurement

In the experimental test, a VIALUX device was used to measure the strain distribution of the tube. Full-field strain analysis done after the forming process is based on the measurement of initially squared grid patterns. This means that the workpiece metal has to be marked before forming. For that purpose, there are standard grid stencils with $1.0-2.0 \mathrm{~mm}$. The grids are well optimized and enable fully automated evaluation of the forming state in many applications. The electrolyte is suited for the electro-chemical marking. In addition, VIALUX also supplies the electrical equipment that is necessary for marking. Fig. 4 shows the results obtained from FLC and the grid of the tube

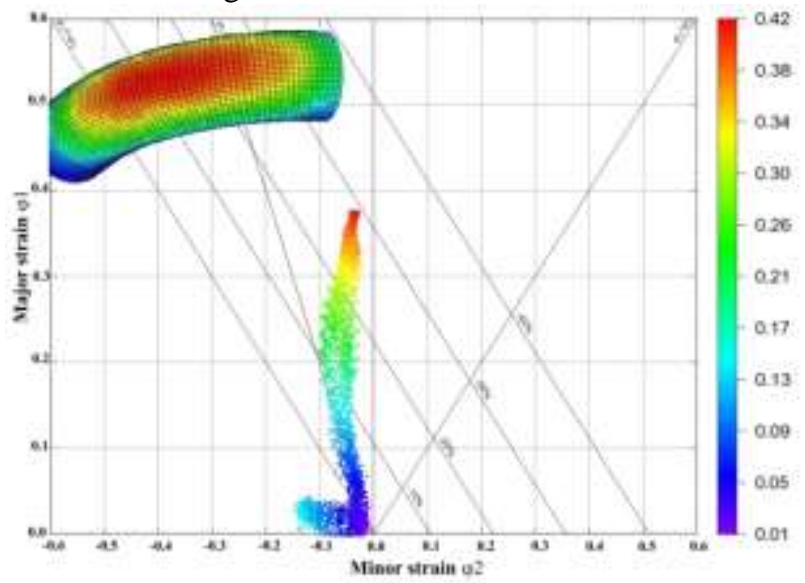

Figure 4: FLC result and the grid of the tube.

\section{Mechanical properties}

It uniaxial tensile tests were performed according to DIN EN ISO 6892-1 and carried out using Z 250 machine. The material characteristics yield strength Rp0.2, tensile strength $\mathrm{R}_{\mathrm{m}}$ and uniform elongation $\mathrm{Ag}$ were obtained using tensile test. In each case, three tensile tests were performed per sample geometry of the material. The averages of mechanical properties are shown in Table I. 
Proc. of the Third Intl. Conf. on Advances in Mechanical and Automation Engineering - MAE 2015.

Copyright (C) Institute of Research Engineers and Doctors, USA .All rights reserved.

ISBN: 978-1-63248-080-4 doi: 10.15224/ 978-1-63248-080-4-28

TABLE I

MAGNETIC PROPERTIES

\begin{tabular}{|c|c|c|c|c|}
\hline $\begin{array}{l}\text { Short } \\
\text { name }\end{array}$ & $\begin{array}{l}3 \\
\stackrel{3}{\overparen{D}} \\
\stackrel{0}{0}\end{array}$ & 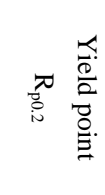 & 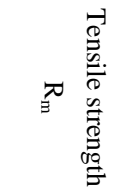 & 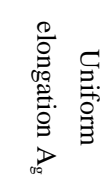 \\
\hline SMo51x7. & $16 \mathrm{M}>$ & 404.8 & 552.9 & 15.7 \\
\hline 1 & 101VIU & 3 & 4 & 2 \\
\hline $\mathrm{SCr} 251 \times 7$ & 10CrMo9 & 342.5 & 506.9 & 13.3 \\
\hline 1 & -10 & 3 & 7 & 6 \\
\hline
\end{tabular}

\section{FINITE ELEMENT SIMULATION}

Finite element simulations of rotary draw bending were performed in the program "PAM-TUBE" to predict the wall thickness distribution, the maximum strain distribution and the neutral axis shifting towards the inner bow of the tube. Fig. 5 shows the finite element model of the rotary draw bending processes.

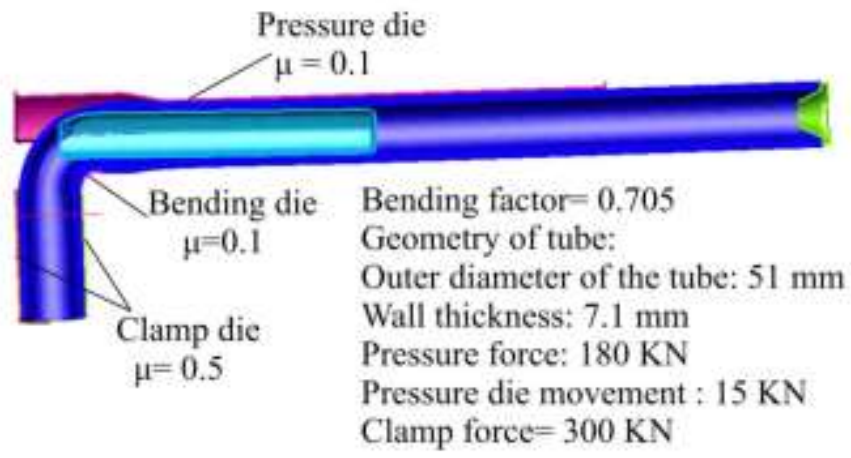

Figure 5: Finite element simulation of the rotary draw bending processes

\section{V.RESULTS AND DISCUSSION}

The thick-walled tube and material properties have influence on the variable characteristics (wall thickness distribution, neutral axis shifting and longitudinal strain distribution) in the tube bending. The FE simulation of the rotary draw bending process is carried out using the program "PAM-Tube". The experimental test and the FE-simulation results are compared with the advanced model that was presented according to [3].

\section{A. Neutral axis shifting}

The neutral axis shifting for different material properties with different bending angles were calculated using FE-simulation as well as experimental tests and model II. The material properties of the tubes are used to bend a tube with special bending parameters those listed in Table II.

TABLE II

BENDING PARAMETERS

\begin{tabular}{ccc}
\hline \hline Material/ & & \\
& SMo51x7.1 & SCr51x7.1 \\
Bending parameters & & \\
\hline & & \\
B (Bending factor) & 0.705 & 0.705 \\
W (Wall factor) & 7.18 & 7.18 \\
Rb (Bending radius) mm & 36 & 36 \\
Lc (Length of the clamp die) mm & 120 & 120 \\
Lp (Length of pressure die) mm & 450 & 450 \\
Fp (Pressure force) KN & 180 & 180 \\
Fc (Clamp force) KN & 300 & 300 \\
Pressure die movement KN & 15 & 15 \\
$\mu \mathrm{c}$ & 0.5 & 0.5 \\
$\left(\mu_{\mathrm{b}}, \mu_{\mathrm{p}}, \mu_{\mathrm{w}}\right.$, and $\left.\mu_{\mathrm{M}}\right)$ & 0.1 & 0.1
\end{tabular}

Fig. 6 and Fig. 7 show that the values of the neutral axis shifting with different bending angles using the experimental tests, the FE-simulated and model II "a plasto-mechancial model". Furthermore, the neutral axis shifting is influenced by the material properties as illustrated in figure 5 and figure 6 .

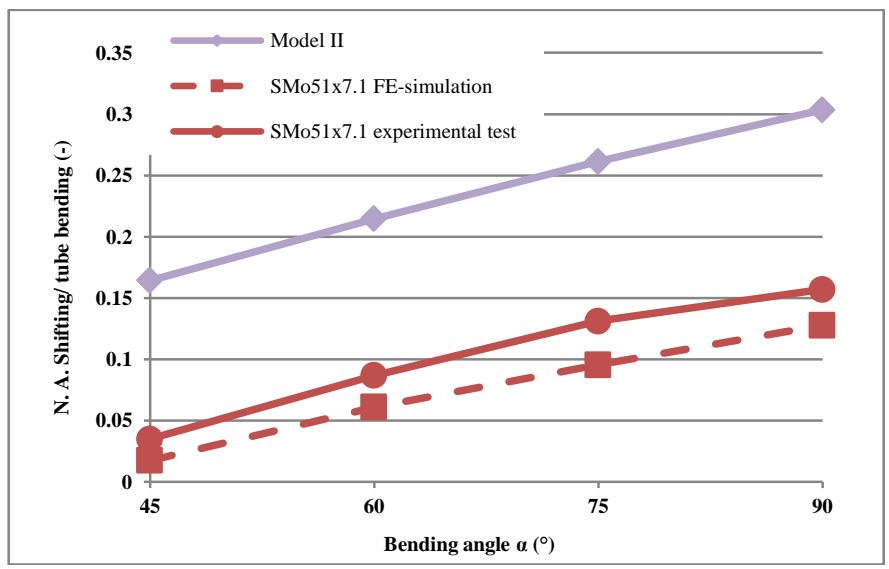

Figure 6: Neutral axis shifting with different bending angle for SMo51x7.1

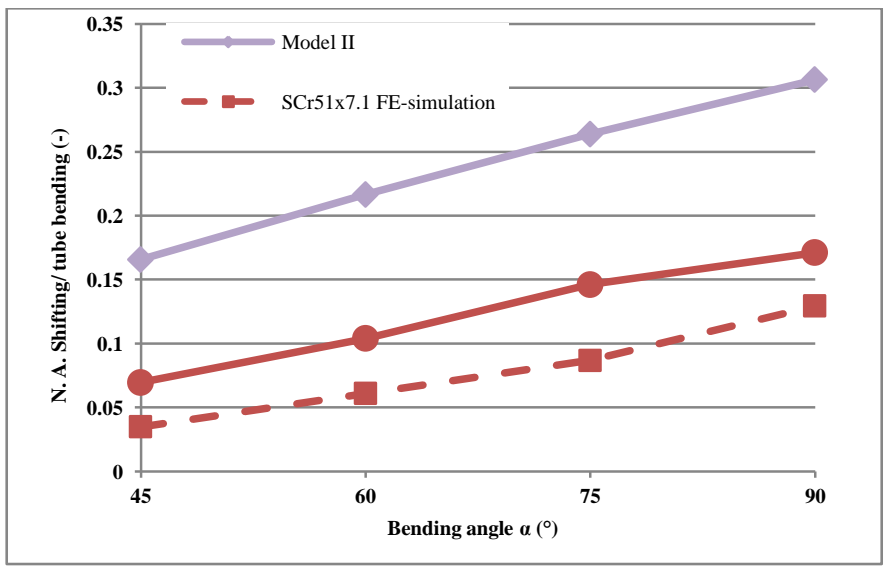


Proc. of the Third Intl. Conf. on Advances in Mechanical and Automation Engineering - MAE 2015.

Copyright (C) Institute of Research Engineers and Doctors, USA .All rights reserved.

ISBN: 978-1-63248-080-4 doi: 10.15224/ 978-1-63248-080-4-28

Figure 7: Neutral axis shifting with different bending angle for SCr51x7.1

\section{B. Wall thickness distribution}

The material properties have influenced on the wall thickness distribution. Fig. 8 and Fig. 9 show that the wall thickness is thinner in the extrados and thicker in the intrados due to tension and compression, respectively. The distribution of the wall thickness in the tube's cross section was in the middle of the bend at a bending angle of $90^{\circ}$. Fig. 8 shows the change in the wall thickness with SMo51x7.1 tube (16Mo3) and Fig. 9 shows the change in the wall thickness with SCr51x7.1 tube (10CrMo9-10).

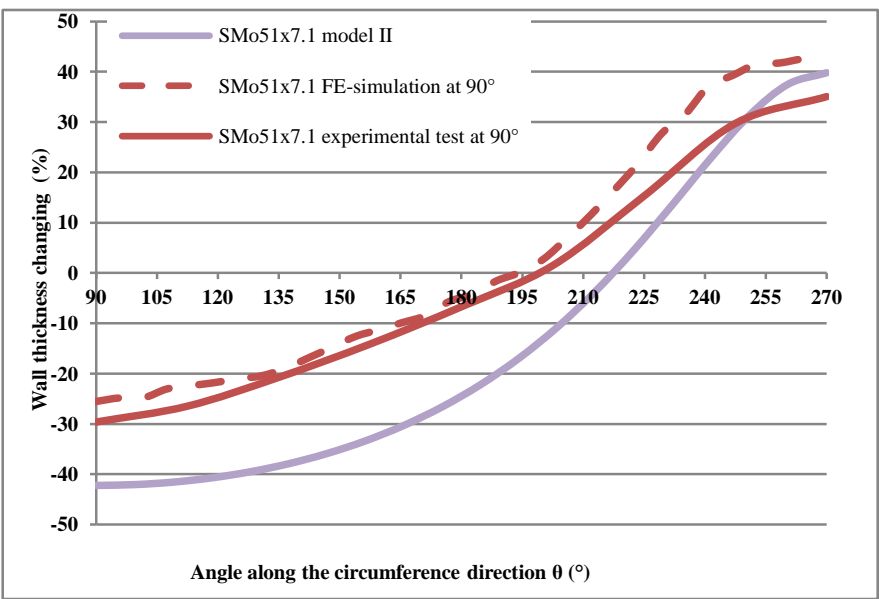

Figure 8: Comparison of the wall thickness distribution in the cross section of the tube for SMo51x7.1

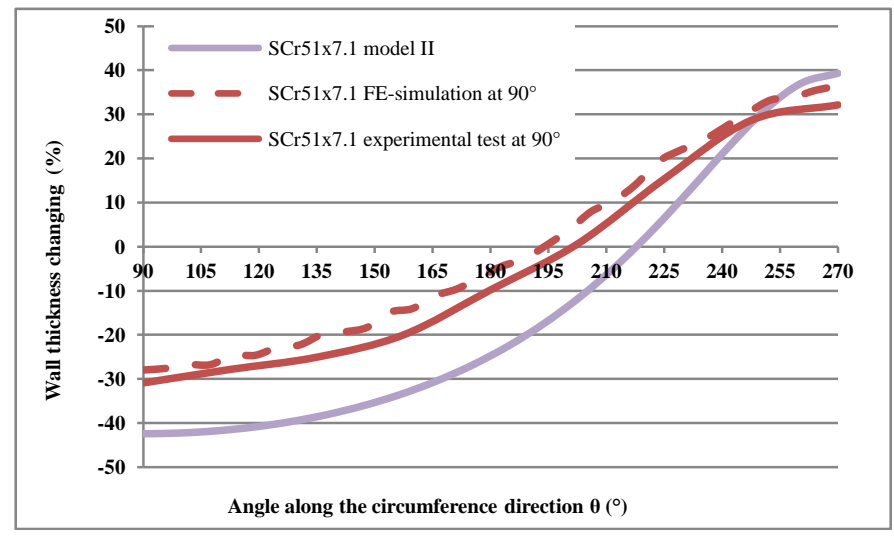

Figure 9: Comparison of the wall thickness distribution in the cross section of the tube SCr51x7.1

\section{Longitudinal strain distribution}

The neutral axis shifting and material properties have an influence on the strain distribution. Fig. 10 and Fig. 11 show the longitudinal strain distribution based on the model II, the FE simulation and the experimental test in the outer arc of the tube that were calculated from the starting angle (bending angle of $0^{\circ}$ ) to half of bending angle. Moreover, the material properties have an influence on the strain values as explained in the figures. It could be found out that the longitudinal strain is higher for steel tubes than for stainless steel tubes due to stress- strain behavior.

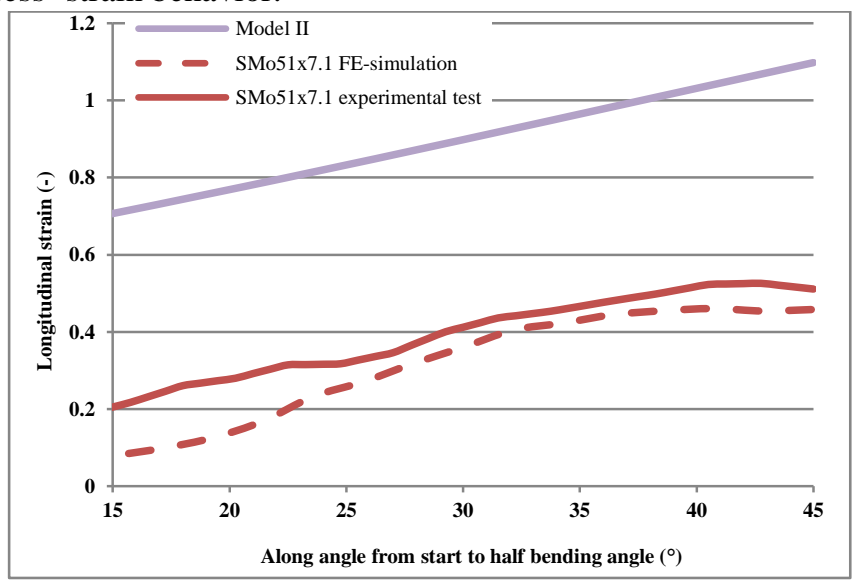

Figure 10: The longitudinal strain of the tube for SMo51x7.1 at bending angle $90^{\circ}$

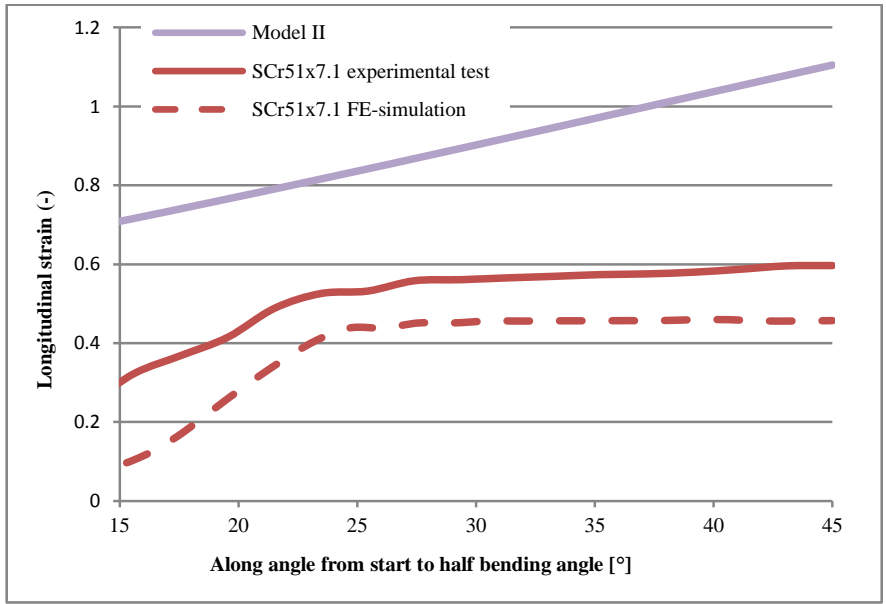

Figure 11: The longitudinal strain of the tube for $\mathrm{SCr} 51 \times 7.1$ at bending angle $90^{\circ}$

\section{CONCLUSION}

In this paper, the influence of the material properties and thick-walled tube on the tube bending with rotary draw bending process has been studied. The experimental tests and FE simulation have been compared with the results of the model II. The neutral axis of the tube moves more towards the inner arc of the tube in steel alloy than in stainless steel alloy. Furthermore, the neutral axis shifting with different material properties have an influence on the wall thickness distribution. The longitudinal strain in the outer arc of the tube is obtained from the experimental tests and the FE simulation. These results have been compared with the results of the model II. Additional, the ovalisation in cross section of the tube has influence on each of the wall-thinning / thickening, neutral axis shifting and strain distribution that was clear in the a palsto-mechanical model " Model II" comparison with experimental tests and finite element results as well. 
Proc. of the Third Intl. Conf. on Advances in Mechanical and Automation Engineering - MAE 2015.

Copyright $(\odot$ Institute of Research Engineers and Doctors, USA .All rights reserved.

ISBN: 978-1-63248-080-4 doi: 10.15224/ 978-1-63248-080-4-28

\section{ACKNOWLEDGMENT}

The author would like to thank the University Siegen and the Ministry of Higher Education and Scientific Research of Iraq for their contribution to this study.

\section{REFERENCES}

[1] Yang H., Sun Z.C., Li M.Q., Advanced plastic processing technology and research progress on tube forming, Journal of Plasticity Engineering (2001) 86-88

[2] Engel B., Hassan, H. (2015), Prediction of the wall thickness distribution of bent tubes manufactured by rotary draw bending process. XXXIV Verformungskundliches Kolloquium Zauchensee von 14.3. to 17.3.2015

[3] Engel B., Hassan H.(2015), Advanced model for calculation of the neutral axis shifting and the wall thickness distribution in rotary draw bending processes, Internation Journal of Mechamnical, Aerospace, Industrial and Mechatronics Engineering Vol:9 No:2, 2015, pp. 171-175.

[4] Duncan J. L., Hu J. (2002), and Marciniak Z., Mechanics of Sheet Metal Forming, Butterworth-Heinemann, Woburn, MA.

[5] Engel B., Hassan H.(2014), Investigation of Neutral Axis Shifting in Rotary Draw Bending Processes for Tubes. Steel research int. 